\title{
申扎-定结正断层体系中、南段构造特征 及其与藏南拆离系的关系
}

\author{
张进江 ${ }^{(1)}$ 郭磊 ${ }^{(1)}$ 丁 $^{(2)}$
}

(1)北京大学地质学系, 北京 100871; (2)中国科学院地质与地球物理研究所, 北京 100029. E-mail: zhjj@pku.edu.cn)

\begin{abstract}
摘要申扎-定结正断层体系是发育于青藏高原中南部的近南北走向大型伸展构造, 其中段发育于特提 斯喜马拉雅地块，由早期岩浆核杂岩和后期向北西西倾斜的中等倾角正断层组成，岩浆核杂岩由糜棱 岩化浅色花岗岩组成, 顶部发育低角度拆离断层, 上覆浅变质沉积岩系. 正断层体系南段表现为具有 典型构造组合特征的、倾向南东东的拆离断层, 下盘为高喜马拉雅岩系. 本区藏南拆离系(STDS)为由糜 棱岩化浅色花岗岩形成的韧性剪切带, 并被时代较晚的申扎-定结正断层体系切割, 说明 STDS 并不是 南北走向伸展构造的控制或调节构造, 而南北走向伸展构造可能是南北向挤压的变形分解产物.
\end{abstract}

\section{关键词 青藏高原 伸展构造 申扎-定结正断层体系(XDNFS) 藏南拆离系(STDS)}

中新世以来, 青藏高原经历了广泛的伸展作用. 这种伸展作用既是对印度与欧亚大陆汇聚的变形调 节, 也与高原隆升密切相关 ${ }^{[1-3]}$. 近南北走向伸展构 造是青藏高原中南部最显著的构造特征之一, 发育 众多正断层体系, 如亚东-谷路裂谷(YGR)、申扎定结正断层体系(XDNFS) 和尼玛-定日正断层体系 (NTNFS)等(图 1). 目前就近南北走向伸展构造的产状 分布和形成机制尚存争议. 就产状分布, 一些学者认 为伸展构造仅分布于喀喇昆仑-嘉黎断裂带(KJFZ)以 南和藏南拆离系(STDS) 以北的拉萨和特提斯喜马拉 雅地块 ${ }^{[4-7]}$, 另一些学者认为伸展构造发育于整个青 藏高原 ${ }^{[8-10]}$. 南北走向伸展构造的成因机制争论 颇 多, 现存的观点包括高原隆升到最大高度后的垮 塌 ${ }^{[11,12]}$ 、块体挤出 ${ }^{[4,5]}$ 、地幔对流 ${ }^{[9]}$ 和岩石圈热结构 调整 ${ }^{[10]}$ 以及南北向挤压的变形分解 ${ }^{[13,14]}$ 等. 另外, 近南北走向伸展构造与近东西走向构造(如 STDS)的 关系也是一个焦点问题, 它既涉及到南北走向伸展 构造的产状分布, 又与其成因密切相关, 有学者认为 南北走向伸展构造是块体挤出的派生产物, 近东西 走向的 KJFZ 和 STDS 是近南北走向伸展构造的边界 控制构造 ${ }^{[4,5,7]}$, 或者近东西走向构造是近南北走向 构造不均一变形的末端调节构造 ${ }^{[9,15]}$. 也有学者认为 近南北走向伸展构造切割近东西走向构造 ${ }^{[16,17]}$. 本 文根据野外考察, 对近南北走向申扎-定结正断层体 系中、南段的构造特征及其与近东西走向 STDS 的关 系进行论证, 并对近南北走向伸展构造的成因进行
初步探讨.

\section{1 区域地质概况}

申扎-定结正断层体系(XDNFS)位于青藏高原中 南部, 北起申扎县以北(图 1), 向北切割 KJFZ 并可追 溯至㒸塘高原中部. 向南至定结附近切过 STDS 而延 人高喜马拉雅地块. 该正断层体系由几个产状和特 征不同的段落组成, 雅鲁藏布江缝合带(YSZ)以北的 北段为倾向南东东的正断层体系, 主要为脆性断层, 靠近 YSZ 发育与岩浆作用相关的低角度拆离断层, YSZ 至 STDS 的中段为北西西倾斜的正断层, STDS 以南的南段则为倾向南东东的拆离断层. 虽然各段 产状不同, 但它们构成一个连贯的伸展构造体系, 地 貌上形成统一的狭长带状负地形. 本文研究区包括 该正断层体系的中、南段大部分地区(图 1，2), 构造 位置横跨 STDS 两侧的特提斯喜马拉雅和高喜马拉 雅地块. 中段的特提斯喜马拉雅地块主要发育印度 大陆北侧稳定陆缘沉积组成的特提斯喜马拉雅岩系, 为古生代(C-P)及中生代(T-J)灰岩、泥岩和石英砂岩, 并发生低级变质而形成板岩、千枚岩等. 南段高喜马 拉雅地块为喜马拉雅逆冲推覆体系中高级结晶岩席 体(高喜马拉雅岩系), 由正、副片麻岩及浅色花岗岩 组成. 特提斯喜马拉雅和高喜马拉雅地块之间以 STDS 分割. 申扎-定结正断层体系呈北北东向切割 上述 3 个构造单元, 形成了研究区最显著的断裂构造 之十3,6中段切割特提斯喜马拉雅地块, 以正断层和岩 


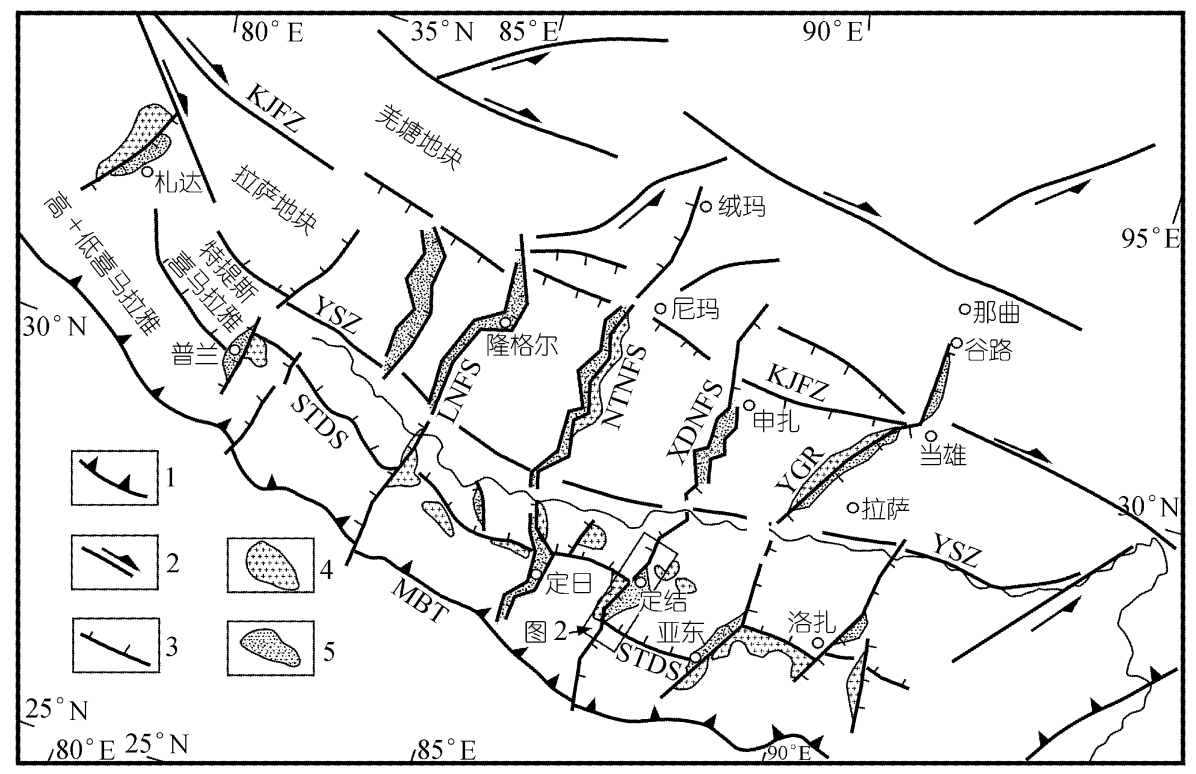

图 1 青藏高原伸展构造示意图及研究区位置

KJFZ: 喀喇昆仑-嘉黎断裂带; YSZ: 雅鲁藏布江缝合带; STDS: 藏南拆离系; MBT: 主边界断裂; LNFS: 隆格尔正断层体系; NTNFS: 尼玛-定日 正断层体系; XDNFS: 申扎-定结正断层体系; YGR: 亚东-谷路裂谷. 1. 逆冲断层; 2. 走滑断层; 3. 伸展断层; 4. 浅色花岗岩; 5. 新生代盆地

浆核杂岩为特征，南段切割高喜马拉雅地块并形成 高喜马拉雅与特提斯喜马拉雅地块的界限，构造以 典型拆离断层为特征.

\section{2 申扎-定结正断层体系中段的正断层及岩 浆核杂岩}

申扎-定结正断层体系在研究区中段特提斯喜马 拉雅地块中以早期岩浆核杂岩和后期正断层为主要 构造特征(图 2). 此段最明显的构造形式为后期中等 倾角的脆性正断层, 断层面走向 30 45 ${ }^{\circ}$, 倾向北西, 倾角 $40 \sim 45^{\circ}$. 正断层地貌特征明显, 上、下盘高程差 别突出, 断层面发育良好, 具典型的断层三角面, 下 盘冰川 U 形谷被断层明显切断, 说明其近期仍有活 动. 除岩浆核杂岩区外，断层上、下盘均为浅变质特 提斯喜马拉雅沉积岩系, 但变质程度略有不同, 下盘 泥岩变质为千枚岩, 上盘一般为板岩.

中段一个最显著的特征是上述正断层下盘发育 一种类似变质核杂岩的构造杂岩体 (图 2,3), 但其内 不具有变质核杂岩的糜棱状深变质岩, 而全部由浅 色花岗岩组成, 上覆早、中三叠世 $\left(\mathrm{T}_{1-2}\right)$ 线变质的千枚 岩和变质砂岩, 岩浆岩与上盘岩石为低角度断层接 触, 这种构造杂岩体被称为岩浆核杂岩 ${ }^{[18]}$. 岩浆核 杂岩核部浅色花岗岩(冷却年龄为中新世中晚期, 王 瑜未发表数据)早期发生统一的塑性流动变形, 矿物
定向排列形成透人性的面理和线理，面理走向在核 杂岩的大部分地区与前述的后期正断层平行, 倾向 北西西, 倾角约 $20^{\circ}$. 在核杂岩北端, 面理走向与岩 浆岩边界一起发生转折, 并在最北端变为向北倾斜, 倾角约 $10^{\circ}$. 尽管面理产状变化较大, 整个岩浆核中 线理产状较稳定, 倾伏方向 $285 \sim 310^{\circ}$, 倾伏角为 2 20 (图 3).

岩浆核杂岩的西北侧被前述大型正断层切割, 北侧与上覆特提斯喜马拉雅岩系千枚岩的接触关系 为早期的低角度正断层. 该低角度断层同样被杂岩 西北侧正断层切割, 走向由西部的北东向变为东部 的近东西向, 倾角为 $15 \sim 20^{\circ}$ (图 3). 断层带上盘为禇 皱的千枚岩, 禇皱倒向指示上盘向北西运动, 该套岩 石的底部发育断层角砾岩, 由角砾和钙质胶结物组 成. 断层下盘为糜棱岩化的浅色花岗岩, 顶部紧邻断 层发育一层厚约 $5 \mathrm{~m}$ 的强变形断层岩, 其前期发生塑 性变形, 形成様棱岩, 其粒度与核部中粒浅色花岗岩 存在明显差别, 様棱岩发生后期碎裂和硅化作用, 硅 化使该层构造岩形成岩浆核杂岩的外壳, 其抗风化 程度和颜色均与核部花岗岩存在明显不同. 由于该 低角度正断层分割了上盘脆性变形域和下盘韧性变 形域, 而且本身变形性质又具有由韧性向脆性的转 变, 所以该断层也可称为拆离断层.

罘浆核染岩内部岩浆岩呈现塑性流动变形-脆韧 


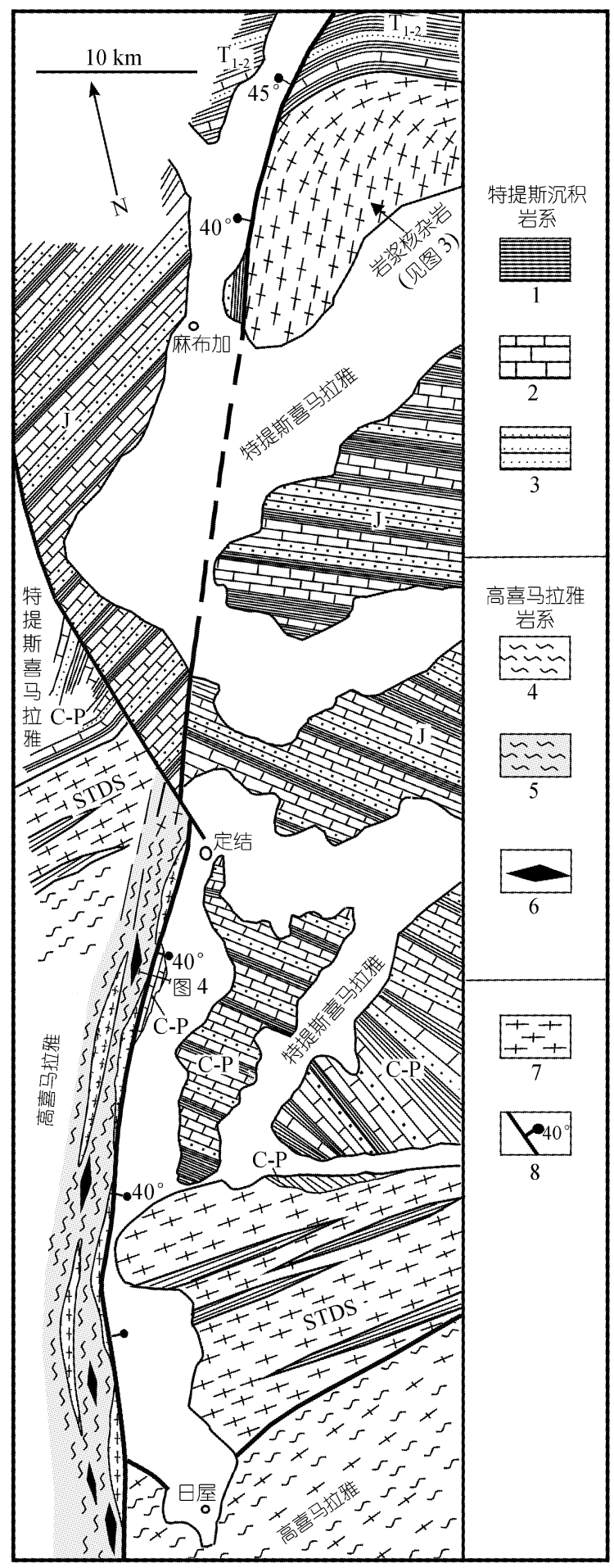

图 2 申扎-定结正断层体系中、南段构造地质图 (定结附近，位置见图 1)

特提斯喜马拉雅沉积岩系: 1 . 板岩及千枚岩; 2 . 灰岩; 3. 砂岩. 高喜 马拉雅岩系: 4. 片麻岩; 5. 糜棱状片麻岩; 6. 榴闪岩包体. 7. 面理线 理化浅色花岗岩; 8. 正断层及其倾角. J: 侏罗纪地层; $\mathrm{T}_{1-2}$ : 早-中三叠 世地层; C-P: 古生代(石炭纪-二叠纪)地层; STDS: 藏南拆离系
性变形-脆性变形的递进演化过程, 塑性流动变形形 成透人性面理和线理，脆韧性变形形成透人性可剥 性面理，脆性变形形成密集脆性破裂面．这些构造面 产状依次变陡, 如在岩浆核杂岩南端(图 3), 糜棱面理、 脆㓞性面理和脆性破裂面的产状依次为 $275^{\circ} \angle 20^{\circ}$, $290^{\circ} \angle 25^{\circ}$ 和 $290^{\circ} \angle 40^{\circ}$. 以上各期构造变形形成不 同的线理，塑性变形形成矿物定向线理，脆韧性面理 面上发育由强拉伸矿物组成的热擦痕, 而脆性破裂 面上则为擦痕. 这些线理在核杂岩南部均为倾向线 理，倾伏向基本为北西西(图 3). 糜棱岩中 S-C 组构、 脆㓞性面理上热擦痕阶步和矿物纤维生长性质、以及 破裂面上的丁头痕等运动学标志均指示上盘向北西 西运动, 即正断下滑, 且与岩浆核杂岩西北侧的正断 层运动方向一致. 由此可见，早期塑性变形到后期脆 性变形具有相同的运动方式, 可能是同一期变形形 成, 虽然这种由韧性向脆性的转变可以用岩浆岩冷 却解释, 但考虑到构造面理依次变陡的事实, 我们认 为这种转换可能是由深部向浅部的转变, 即代表岩 浆核杂岩的隆升演进系列.

\section{3 申扎-定结正断层体系南段的拆离断层}

自定结往南，申扎-定结正断层体系南段的构造 形式为具有拆离断层构造组合的正断层, 断层走向 约 $20^{\circ}$, 倾向南东东, 倾角 $40 \sim 50^{\circ}$ (图 2). 断层最北 端切过特提斯喜马拉雅与高喜马拉雅地块之间的浅 色花岗岩系, 向南, 下盘为高喜马拉雅岩系片麻岩夹 浅色花岗岩及榴闪岩包体. 上盘北部为特提斯喜马 拉雅浅变质沉积岩系(C-P), 中部为特提斯喜马拉雅 与高喜马拉雅地块之间的浅色花岗岩系, 南部则为 高喜马拉雅岩系的眼球状片麻岩.

该断层具有典型的拆离断层构造组合，断层面 保存良好, 形成发育擦痕和擦面的抛光面, 并与被切 割的冰川 $\mathrm{U}$ 形谷形成完美的断层三角面, 典型的断 层面产状为 $120^{\circ} \angle 40^{\circ}$. 断层面之下为拆离断层构 造岩系列, 在图 4 所示剖面上(位置见图 2), 紧邻断层 面为 $10 \mathrm{~m}$ 厚的浅灰绿色硅化微角砾岩, 由外表类似 硅质岩的超碎裂岩组成; 微角砾岩之下是 $30 \mathrm{~m}$ 厚的 灰绿色绿泥石化角砾岩, 由碎裂的糜棱状片麻岩和 花岗岩形成; 碎裂岩下为糜棱状片麻岩和浅色花岗岩, 其内含有角闪岩、榴闪岩包体. 该套岩石经历了强烈 的㓞性变形形成糜棱状片麻岩, 长石、石英等矿物被 强烈拉伸, 云母、角闪石等定向排列, 形成岩石内透 人性糜棱面理和线理, 面理产状为 $100 \sim 115^{\circ}$ 


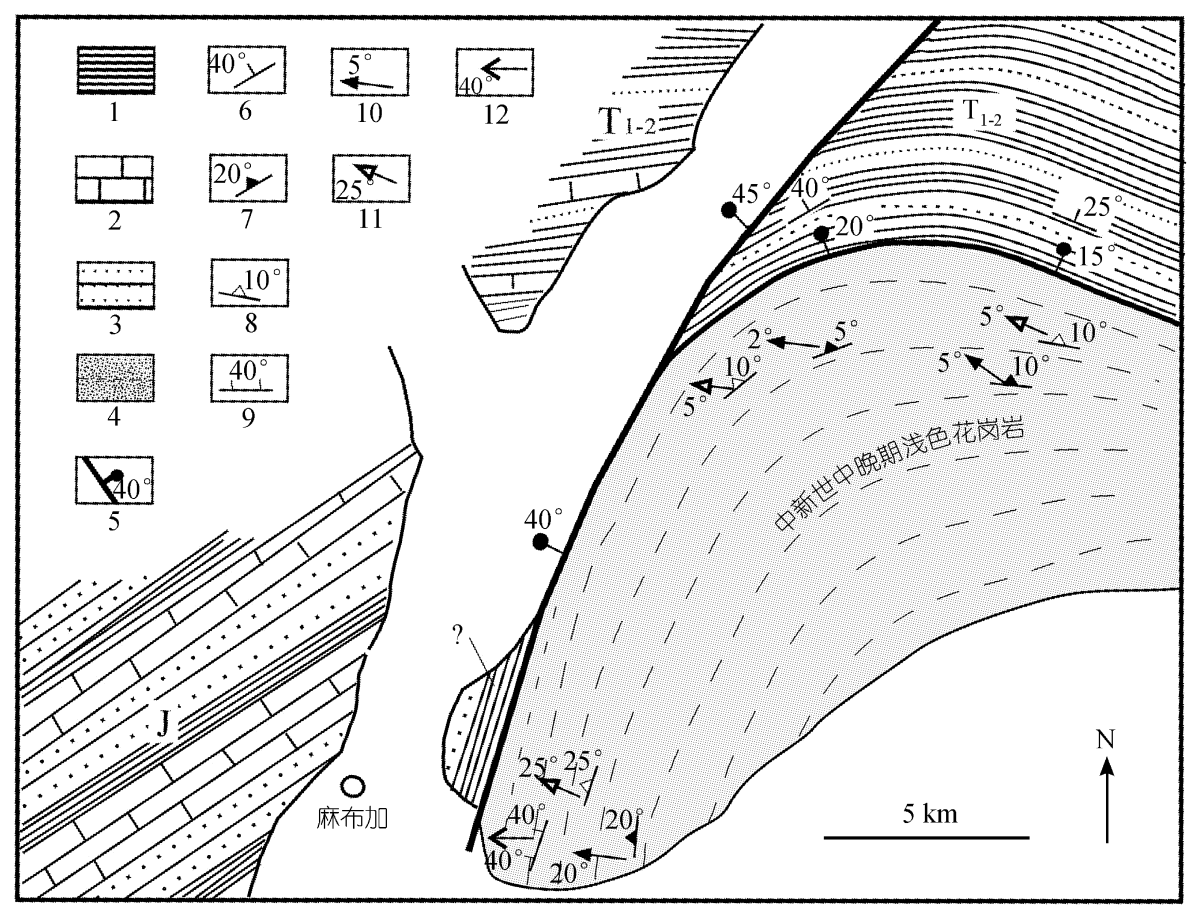

图 3 申扎-定结正断层体系中段岩浆核杂岩构造地质图(地层时代符号及位置见图 2)

1. 板岩及千枚岩; 2. 灰岩; 3. 砂岩; 4. 面理线理化浅色花岗岩; 5. 正断层及其倾角; 6. 岩层产状; 7. 糜棱面理及产状; 8. 脆韧性面 理及产状; 9. 脆性破裂面及产状; 10. 糜棱线理及产状; 11. 脆韧性面理上的热擦痕及产状; 12 . 脆性破裂面擦痕及产状

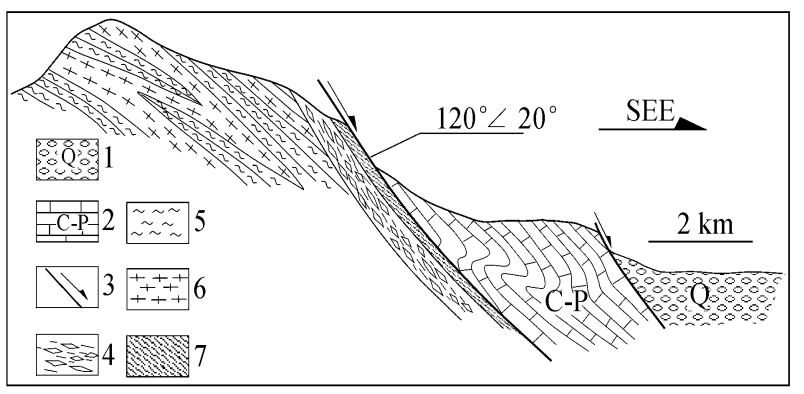

图 4 定结以南申扎-定结正断层体系拆离断层的构造剖 面图(地层时代符号及位置见图 2)

1. 第四纪沉积; 2. 古生代灰岩; 3. 正断层; 4. 绿泥石化角砾岩;

5. 糜棱状片麻岩; 6. 糜棱状浅色花岗岩; 7. 硅化微角砾岩

$\angle 30 \sim 35^{\circ}$, 线理产状 $135 \sim 145^{\circ} \angle 20 \sim 30^{\circ}$. 不对称眼 球构造和 S-C 组构等指示其运动性质为具右行走滑 性质的正断层, 该运动的水平右行运动分量将特提 斯喜马拉雅与高喜马拉雅地块之间的界限(STDS)错 断了近 $30 \mathrm{~km}$ (图 2).

拆离断层下盘片麻岩中发育不同形态的浅色花 岗岩, 根据变形形态和矿物组成, 浅色花岗岩可大致 分为两套, 一套为顺层侵位的白云母花岗岩, 它们发 生塑性变形, 形成糜棱状花岗岩, 变形性质及运动方 式与片麻岩相同. 另一套为含少量黑云母的浅色花
岗岩和细粒的石榴石浅色花岗岩, 该套花岗岩形成 稍晚期并多沿片麻岩中的裂隙侵位, 它们变形微弱, 只有个别岩体呈现微弱的定向构造. 在图 4 剖面上, 拆离断层的上盘为稍有大理岩化的灰岩(地层时代为 C-P).

\section{4 申扎-定结正断层体系与藏南拆离系 (STDS)的关系}

藏南拆离系(STDS) 是一特大型拆离断层体系, 拆离作用使特提斯喜马拉雅岩系浅变质沉积岩系直 接叠置于高喜马拉雅深变质岩系之上, 形成喜马拉 雅造山带的一条重要的地质界限 ${ }^{[2,19 ~ 24]}$. 在本文研究 区，STDS 没有发育明显的断面构造，而是出露于特 提斯喜马拉雅和高喜马拉雅地块间的、厚度达十几公 里的浅色花岗岩(图 2), 花岗岩发生强烈变形而糜棱岩 化, 形成一规模巨大的韧性剪切带. 该剪切带在研究 区的走向约为 $\mathrm{N} 50 \sim 70^{\circ} \mathrm{E}$ ，其间明显被近南北走向的 申扎-定结正断层体系切割, 正断层体系两侧的 STDS 被右行错断近 $30 \mathrm{~km}$ (图 2).

申扎-定结正断层体以西, STDS 剪切带宽约 $8 \mathrm{~km}$, 由含电气石浅色花岗岩组成, 岩体内含有与糜棱面 理平行的沉积岩层状包体，一般变质为片岩. 糜棱状 
浅色花岗岩内面理产状为 $320^{\circ} \angle 45^{\circ}$, 电气石定向 排列形成的线理产状为 $340^{\circ} \angle 40^{\circ}$, 不对称构造等 运动学标志指示上盘下滑. 剪切带上盘由特提斯喜 马拉雅的石炭-二叠纪变质砂岩、板岩和灰岩组成, 靠近岩体处为千枚岩. 上盘岩石发生禇皱, 但线理与 糜棱状花岗岩一致, 倾伏向约 $340^{\circ}$, 小型褶皱、嬖理 产状等运动学标志指示与剪切带相同的运动方式.

申扎-定结正断层体系以东, STDS 剪切带宽约 $15 \mathrm{~km}$, 由糜棱岩化白云母浅色花岗岩组成, 其内糜 棱面理产状为 $340^{\circ} \angle 30^{\circ}$, 线理 $35^{\circ} \angle 20^{\circ}$. 糜棱状 花岗岩中发育良好的 S-C 组构, S-C 面理关系指示剪 切运动为右行正断.

关于近南北走向伸展构造和近东西走向 STDS 的关系, 有学者认为前者是块体挤出的派生产物, STDS 是其边界控制构造 ${ }^{[4,5,7]}$, 或东西走向构造是近 南北走向构造不均一变形的末端调节构造 ${ }^{[9,15]}$. 也有 学者认为南北走向伸展构造切割了近东西走向构 造 ${ }^{[16,17]}$. 本次研究发现近南北走向的申扎-定结正断 层体系切割了 STDS, 最显著的切割证据是申扎-定 结正断层体系将 STDS 的浅色花岗岩剪切带右行错 断了近 $30 \mathrm{~km}$, 而且该正断层体系向北延人特提斯喜 马拉雅, 向南则切人高喜马拉雅(图 2). 在申扎-定结 正断层体系与 STDS 剪切带的相交部位, 属于申扎定结正断层体系的 NNE 走向面理明显叠加在属于 STDS 的 NEE 走向面理之上, 说明申扎-定结正断层 体系发育晚于 STDS.

Murphy 等人 ${ }^{[24]}$ 曾指出, 珠穆朗玛地区南北走向 和近东西走向的正断层体系同属于 STDS, 是断层的 弯曲转折. 但在本文研究区, 除上述明显的切割关系 外, 构造及组成特征表明, 近南北走向的拆离断层和 近东西走向的 STDS 为不同的构造体系. 首先在运动 协调性上, STDS 总体为向北下滑的正断层, 如果近 南北走向的拆离断层是 STDS 的一部分, 它应该是具 左行性质的正断层, 但事实上近南北走向的拆离断 层具右行正断层性质. 其次, 在岩石组成上, STDS 主 要由糜棱状浅色花岗岩组成, 而近南北走向的拆离 断层不发育大规模的花岗岩体, 只是一些顺层或沿 裂隙灌人的小型岩脉. 第三, 构造特征上, STDS 的下 盘为颗粒粗大的眼球状片麻岩, 变形程度不高, 而近 南北走向拆离断层的下盘为强烈糜棱岩化的片麻岩, 其细粒化程度比 STDS 之下的片麻岩高得多. 另外, 研究区高喜马拉雅岩系中发育许多榴闪岩包体, c这
些包体仅发育于近南北走向拆离断层的西侧下盘, 在拆离断层以东的高喜马拉雅岩系中尚未发现, 显 微镜下分析表明这些包体可能是超高压变质体的残 余, 且经历了两期退变质作用. 这是否说明, 拆离断 层下盘在经历 STDS 正断抬升后, 再次经受南北走向 拆离断层的正断作用, 使其进一步抬升, 使更深部的 地壳出露地表.

同位素年代学研究也证实了 STDS 和 XDNFS 的 不同, STDS 活动的起始时间比近南北走向的正断层 体系要早, STDS 至少在 $17 \mathrm{Ma}$ 时已经开始活动 ${ }^{[9,24]}$, 甚至可以追溯到 $21 \mathrm{Ma}^{[25]}$. 而青藏高原近南北走向正 断层伸展构造较可靠的开始时代为 $14 \mathrm{Ma}$ 左右 ${ }^{[9,10]}$, 并可能持续至更新世 ${ }^{[8,15]}$.

总之, 在近南北走向申扎-定结正断层体系与近 东西走向 STDS 的关系上, STDS 形成早于申扎-定结 正断层体系, 且被后者切割, 定结以南的近南北走向 拆离断层并不是 STDS 的弯曲部分, 而是申扎-定结 正断层体系的一部分. 因此, 东西走向的 STDS 既不 是南北走向伸展构造的控制构造, 也不是南北走向 伸展构造的末端调节构造.

\section{5 近南北走向伸展构造的成因讨论}

关于近南北走向伸展构造的成因还存在不同认 识, 已有的成因模式包括青藏高原隆升至最大高度 后的垮塌、块体挤出、同造山垮塌 ${ }^{[1,3]}$ 以及大陆斜向 碰撞边界条件的改变 ${ }^{[26]}$ 等. 也有不少学者认为它们 是南北向挤压的变形分解 ${ }^{[13,14,27]}$. 我们的研究认为, 南北走向伸展构造可能是南北向挤压的变形分解, 其原因如下:

首先，青藏高原的主隆升可能发生于南北走向 伸展构造之后, 南北走向伸展构造的形成开始于 $14 \mathrm{Ma}$ 左右并持续活动至更新世 ${ }^{[10,11,14]}$, 而青藏高原 达到最大高度的时间可能是 $8 \mathrm{Ma}$ 以后 ${ }^{[28,29]}$, 并且青 藏高原在上新世 更新世仍在强烈隆升 ${ }^{[30 \sim 32]}$. 所以南 北走向伸展构造可能不是青藏高原隆升到最大高度 后的垮塌结果.

其次, 从本文述及的 STDS 与近南北走向伸展构 造的切割关系可以看出, 南北走向伸展构造与东西 走向构造可能不是同一期构造, 所以也可能不是块 体挤出的派生构造.

第三, 大区域上, 南北走向伸展构造的平面形态 为 “朰”字形, 属追踪张断裂体系(图 1), 指示近南北 
向挤压的应力状态，这已被近期的模拟试验所 证实 ${ }^{[33]}$. 同时在喜马拉雅造山带西段札达附近(图 1), 平行于造山带的伸展和垂直于造山带的挤压同时形 成 ${ }^{[14]}$. 因此, 我们认为南北走向伸展构造是南北向 挤压的变形分解.

致谢本工作受高等学校全国优秀博士学位论文作者专 项资金(批准号: 200022)、国家自然科学基金(批准号: 49802020, 40172074)和国家重点基础研究发展规划项目 (批准号: G1998040800)资助.

\section{参考文献}

1 Molnar P, Tapponnier P. Active tectonics of Tibet. J Geophys Res, 1978, 83: 5361 5375

2 Burchfiel B C, Royden L H. North-south extension within the convergent Himalayan region. Geology, 1985, 13: 679 682

3 England P C, Houseman G A. The mechanics of the Tibetan plateau. Phil Tans R Soc Lond, 1986, 326: 301 320

4 Armijo R, Tapponnier P, Mercier J P T, et al. Quaternary extension in southern Tibet. J Geophys Res, 1986, 91: 13803 13872

5 Armijo R, Tapponnier P, Han T. Late Cenozoic right-lateral strike-slip faulting across southern Tibet. J Geophys Res, 1989, 94: 2787 2838

6 Le Fort P. Manaslu leucogranite, a collisional signature of the Himalaya, a model for its genesis and emplacement. J Geophys Res, 1981, 86: 10545 10568

7 Searle M P. Cooling history, erosion, exhumation, and kinematics of Himalaya-Karakoram-Tibet orogenic belt. In: Yin A, Harrison T M, eds. The Tectonic Evolution of Asia. New York: Cambridge University Press, 1996. 109 137

8 Yin A, Kapp P A, Murphy M A, et al. Significant late Neogene east-west extension in northern Tibet. Geology, 1999, 27: 787 790

9 Yin A, Harrison T M. Geologic evolution of the HimalayanTibetan orogen. Annu Rev Earth Planet Sci, 2000, 28: 211 280

10 Blisniuk P M, Hacker B R, Glodny J, et al. Normal faulting in central Tibet since at least $13.5 \mathrm{Myr}$ ago. Nature, 2001, 412: 628 632

11 Coleman M, Hodges K. Evidence for Tibetan plateau uplift before $14 \mathrm{Myr}$ age from a new minimum age for east-west extension. Nature, 1995, 374: 49 52

12 Searle M P. The rise and fall of Tibet. Nature, 1995, 347: 17 18

13 Seeber L, Pêcher A. Strain partitioning along the Himalayan arc and the Nanga Parbat antiform. Geology, 1998, 26: 791 794

14 张进江, 丁林, 钟大麥, 等. 喜马拉雅平行于造山带伸展: 是垮 塌的标志还是挤压隆升过程的产物? 科学通报, 1999, 44: 2031 2036

15 Hurtado J M, Hodges K V, Whipple K X. Neotectonics of the Takkhola Graben and implications for recent activity on the South Tibetan Fault System in the central Nepalese Himalaya. Geol Soc Am Bull, 2001, 113: 222 240
16 Edwards M A, Harrison T M. When did the roof collapse? Late Miocene north-south extension in the high Himalaya revealed by $\mathrm{Th}-\mathrm{Pb}$ monazite dating of the Khula Kangri granite. Geology, 1997, 25: 543 546

17 Wu C, Nelson K D, Wortman G, et al. Yadong cross structure and South Tibetan Detachment in the east central Himalaya $\left(89^{\circ}-90^{\circ} \mathrm{E}\right)$. Tectonics, 1998, 17: 28 45

18 Liu J, Liu Y, Chen H, et al. The inner zone of the Liaoji Paleorift: Its early structural style and structural evolution. J Asian Earth Sciences, 1997, 15(1): 19 31

19 Burg J P, Brunel M, Gapais D, et al. Deformation of the crystalline main central sheet in south Tibet (China). J Struct Geol, 1984, 6: 535 542

20 Copeland P, Parrish R R, Harrison T M. Identification of inherited radiogenic $\mathrm{Pb}$ in mozazite and its implications for U-Pb systematics. Nature, 1988, 333: 760 763

21 Burchfiel B C, Chen Z, Hodges K V, et al. The south Tibetan detachment system, Himalayan orogen, Extension contemporaneous with and parallel to shortening in a collisional mountain belt. Geol Soc Am Special Paper, 1992, 269: 41

22 Harrison T M, Copeland P, Kidd W, et al. Activation of the Nyainqentanglha Shear Zone, applications for uplift of the southern Tibet Plateau. Tectonics, 1995, 14: 658 676

23 Fielding E J. Tibet uplift and erosion. Tectonophysics, 1996, 260: $55 \sim 84$

24 Murphy M A, Harrison T M. Relationship between leucogranite and the Qomolangma detachment in Rongbuk Valley, south Tibet. Geology, 1999, 27: 831 834

25 Noble S R, Searle M P. Age of crustal melting and leucogranite formation from $\mathrm{U}-\mathrm{Pb}$ zircon and monazite dating in the western Himalaya, Zanskar, India. Geology, 1995, 23: 1135 1138

26 McCafery R, Nabelek J. Role of oblique convergence in the active deformation of the Himalaya and southern Tibetan Plateau. Geology, 1998, 26: 691 694

27 Ratschbacher L, Frisch W, Liu G, et al. Distributed deformation in southern and western Tibet during and after the India-Asia collision. J Geophys Res, 1994, 99: 19917 19945

28 Harrison T M, Copeland P, Kidd W S F, et al. Raising Tibet. Science, 1992, 255: 1663 1670

29 Pan Y, Kidd W S F. Nyainqentanghla shear zone, A late Miocene extensional detachment in the southern Tibetan Plateau. Geology, 1993, 20: 775 778

30 李吉均. 青藏高原隆升的时代、幅度和形式探讨. 中国科学, 1979, (6): 608 616

31 丁林, 钟大㐘, 潘裕生, 等. 东喜玛拉雅构造结上新世以来快速 抬升的裂变径迹证据. 科学通报, 1995, 40: 1497 1500

32 钟大㐘, 丁林. 青藏高原隆起过程及其机制探讨. 中国科学, D 辑, 1996, 26: 289 295

33 潘裕生. 青藏高原新新生代变形模拟实验结果. 地质科学(待发 表) 